\title{
Strategies towards in vivo imaging of active transglutaminase type 2 using positron emission tomography
}

\author{
Berend van der Wildt ${ }^{1,2}$ (D) Adriaan A. Lammertsma ${ }^{1}$ - Benjamin Drukarch ${ }^{2}$. \\ Albert D. Windhorst ${ }^{1}$
}

Received: 10 May 2016 / Accepted: 22 June 2016 / Published online: 5 July 2016

(C) The Author(s) 2016. This article is published with open access at Springerlink.com

\begin{abstract}
Transglutaminase type 2 (TG2) is increasingly linked to the pathogenesis of several diseases, such as celiac disease, cancer, and fibrotic and neurodegenerative diseases. In parallel with becoming an attractive target for therapy, interest in the development of compounds for in vivo imaging of TG2 is rising. Such imaging biomarkers might assist in clarifying the role of TG2 in pathology and in monitoring TG2 inhibition in vivo and thus assist in drug development. In this review, the latest results together with various strategies in TG2 PET tracer development are discussed, including radiolabelling of irreversible and reversible active-site inhibitors, as well as allosteric inhibitors, acyl-donor and acyl-acceptor substrates, and anti-TG2 monoclonal antibodies.
\end{abstract}

Keywords Transglutaminase type 2 - PET · Irreversible TG2 inhibitors · Reversible TG2 inhibitors · Substrates · Antibodies

$\begin{array}{ll}\text { Abbreviations } \\ \text { BAP } & \text { 5-(Biotinamido)-pentylamine } \\ \text { BBB } & \text { Blood brain barrier } \\ \text { B }_{\max } & \text { Maximum binding sites } \\ \text { dGTP } & \text { Deoxyguanosine triphosphate } \\ \text { DTT } & \text { Dithiothreitol }\end{array}$

Handling Editors: S. Beninati, M. Piacentini, C.M. Bergamini.

Berend van der Wildt

b.vanderwildt@vumc.nl

1 Departments of Radiology and Nuclear Medicine, VU University Medical Center, Amsterdam, The Netherlands

2 Departments of Anatomy and Neurosciences, VU University Medical Center, Amsterdam, The Netherlands

$\begin{array}{ll}\text { EGF } & \text { Endothelial growth factor } \\ \text { FXIIIa } & \begin{array}{l}\text { Activated subunit A of blood coagulation } \\ \text { factor XIII }\end{array} \\ \text { GTP } & \text { Guanosine triphosphate } \\ \text { GTP } \gamma \mathrm{S} & \begin{array}{l}\text { Guanosine } 5^{\prime}-O \text {-[gamma-thio]triphosphate } \\ \text { IC }\end{array} \text { Inhibitor concentration resulting in 50\% } \\ & \text { inhibition } \\ K_{\mathrm{d}} & \text { Dissociation constant } \\ \text { LC-MS/MS } & \text { Liquid chromatography-tandem mass } \\ & \text { spectrometry } \\ \text { PBS } & \text { Phosphate buffered saline } \\ \text { PET } & \text { Positron emission tomography } \\ \text { PH } & \text { Pulmonary hypertension } \\ \text { SAR } & \text { Structure-activity relationship } \\ \text { TG2 } & \text { Transglutaminase type 2 }\end{array}$

\section{Introduction}

Positron emission tomography is a non-invasive imaging technique that allows for quantitative imaging of biological processes (Phelps 2000; Czernin and Phelps 2002; Bergström et al. 2003; Jones and Rabiner 2012). PET depends on the incorporation of unstable $\beta^{+}$emitting nuclides, i.e., nuclides with a neutron deficiency, into biologically relevant molecules. After emission, these positively charged particles, so-called positrons, having a mass equal to that of electrons will collide with electrons in tissue, thereby losing their kinetic energy. Ultimately, a positron will combine with a nearby electron after which the two particles will annihilate, resulting in the emission of two $511 \mathrm{keV}$ photons travelling in opposite direction due to the conservation of angular momentum. Co-incidence detection of these two photons by detectors (often positioned in a circular detector ring), identifies the line of response along 


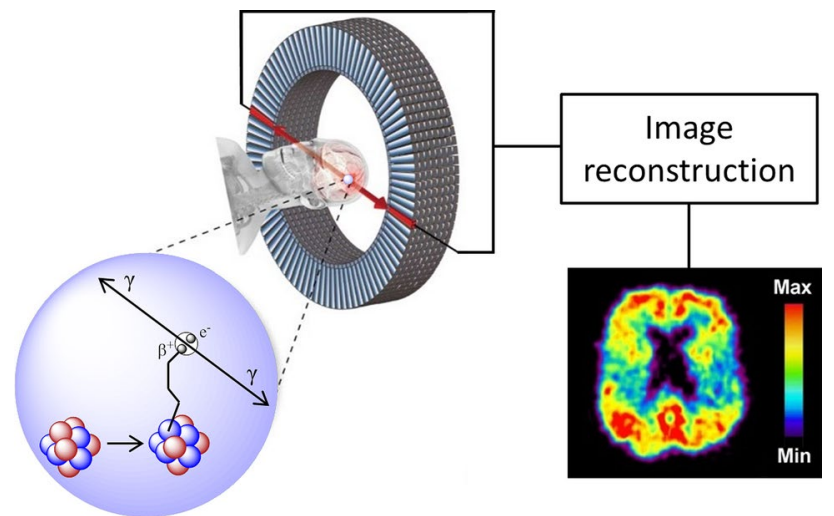

Fig. 1 Basic principles of PET. A PET nuclide, incorporated in a biologically relevant molecule, decays and emits a positron inside a subjects' brain. Following annihilation with a nearby electron (depicted as $\mathrm{e}^{-}$), two $511 \mathrm{keV}$ photons are formed, which travel in opposite directions and are detected simultaneously by two opposing (in coincidence) detector elements within the PET detector ring. Combining co-incidence counts from all detector pairs allows for reconstruction of the quantitative distribution of the radioactive ligand in three-dimensional space

which the annihilation took place. Subsequent processing of a large number of such co-incidence events ultimately leads to a three-dimensional map, reflecting the original distribution of the injected radiotracer (Fig. 1). Biologically relevant molecules, in which positron emitting nuclides can be incorporated, include small organic compounds, such as enzyme inhibitors or substrates, receptor agonists or antagonist, and peptides and biologicals, such as monoclonal antibodies and fragments (Miller et al. 2008; van Dongen et al. 2007). The obtained radiopharmaceutical or PET tracer is applied in molecular imaging with PET.

The radiochemistry that is applied to synthesize the PET tracers differs drastically from the traditional organic chemistry in that high sub-stoichiomectric amounts of radioactive reagent, typically in the nanomole range, are reacted with micromolar amounts of the other reagents. The large excess of reagents relative to the small amount of radioactive reagent allows for rapid reactions, compatible with the short radionuclide half-lives. Furthermore, the small scale of the reactions enables rapid purification by means of preparative HPLC. PET tracers are typically obtained in sterile and isotonic injectable solutions and are administered intravenously, allowing for rapid distribution throughout the subject. As a result of the nanomole amounts of tracer compound administered, no biological effects are anticipated, making PET a purely analytical diagnostic imaging modality (Miller et al. 2008). Moreover, PET is a fast and quantitative molecular imaging technique allowing for dynamic molecular imaging and assessment of parameters, such as $B_{\max }, K_{\mathrm{d}}$, and receptor occupancy, amongst others (Bergström et al. 2003).
For PET imaging using small organic molecules, carbon-11 and fluorine-18 are commonly the nuclides of choice (Miller et al. 2008). Their physical half-lives of 20.3 and $110.8 \mathrm{~min}$ are compatible with the in vivo kinetics of such small molecules. Radiosynthesis of these radiotracers is limited by their short half-lives, resulting in limited synthetic toolboxes compared with those in the traditional organic chemistry. Therefore, not all compounds are amenable for radiosynthesis and analogues of those lead compounds may be necessary. In general, monoclonal antibodies do allow for radiolabelling, for example, by modification of lysine residues with a radiometal chelating moiety (Vosjan et al. 2010). Due to their slower kinetics, usually longer lived radionuclides, such as $\mathrm{Cu}-64, \mathrm{Zr}-89$, and I-124, are used (van Dongen et al. 2007).

The choice of biologically active compounds for radiolabelling usually is driven by several factors, the location of the biological target being dominant in this selection. Targets located intracellularly or in the central nervous system can only be reached via passive diffusion using small non-polar organic compounds (Pike 2009), whereas extracellular or membrane bound peripheral targets can also be reached using bulkier molecules, such as peptides and antibodies. Furthermore, lead compounds are generally selected based on affinity, selectivity, and metabolic stability (Pike 2009). As PET only measures the distribution of radioactivity and not the chemical form, it is important to carefully study metabolism of a putative radioligand (Pike 2009). At present, the in vivo kinetics of existing TG2 inhibitors which are largely unknown and metabolism data, if available, is largely depending on in vitro plasma or hepatocyte stability data (Wityak et al. 2012; Prime et al. 2012a, b; Badarau et al. 2015). This limited availability of stability data hampers selection of high-potential compounds for translation to PET agents. Radiolabelling of a TG2 inhibitor, however, allows for following its distribution as well as its metabolic stability (Van der Wildt et al. 2016). Furthermore, because of increased sensitivity of LC-MS/MS, formed metabolites may be chemically characterized ex vivo (Ma et al. 2010).

Transglutaminases comprise a class of structurally related enzymes containing eight catalytically active family members, named TG1-TG7 and FXIII (Griffin et al. 2002). These enzymes are well known for their ability of cross-linking proteins by forming an intermolecular isopeptide bond, more specifically an epsilon-(gamma-glutamyl) lysine bond, between the side chains of a glutamine residue as an acyl-donor substrate and a lysine residue of an acyl-acceptor substrate. These isopeptide bonds are highly stable towards proteolysis and introduce mechanical stability in tissues (Griffin et al. 2002). Transglutaminase type 2, TG2, plays an important role during apoptosis by intracellular cross-linking of cellular components, thereby 


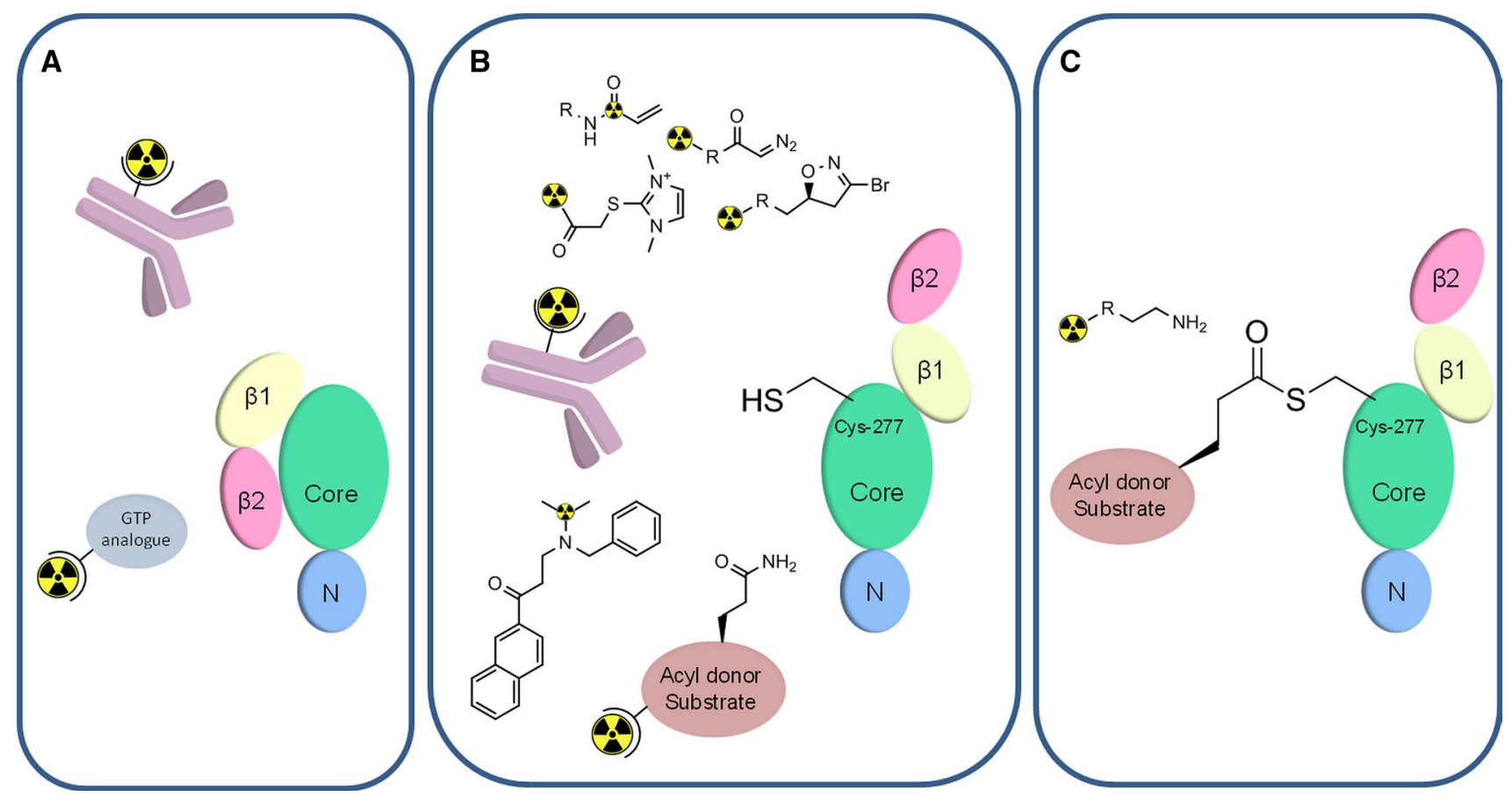

Fig. 2 Potential strategies for TG2 PET imaging. a Closed conformation TG2 can be targeted by either radiolabelled antibodies or GTP site binding molecules; b open conformation TG2 can be targeted by radiolabelled irreversible inhibitors, TG2 antibodies, reversible inhibitors, or acyl-donor substrates; $\mathbf{c}$ intermediate thioester between acyl-donor substrate and TG2 that can be intercepted by radiolabelled nucleophiles, such as amines

and low GTP/GDP concentrations allow TG2 mediated cross-linking. In addition, TG2 cross-linking activity is regulated by the redox state of the enzyme, as a disulfide bond between cysteine 370 and cysteine 371 induces cross-linking inactivation of TG2 (Stamnaes et al. 2010). In addition, by forming ternary protein complexes with integrins and fibronectin, as well as by nitrosylation (Santhanam et al. 2010), TG2 cross-linking activity might be limited (Siegel et al. 2008). Local increases in cross-linking activity of TG2 in vivo may be induced by various molecular stimuli, including retinoids, EGF, and sphingophospholipids (Singh et al. 2001; Antonyak et al. 2009; Lai et al. 1997).

Aberrant TG2 expression and/or activity are increasingly associated with the pathogenesis of a number of disorders, e.g., autoimmune diseases, fibrotic diseases, cancer, and diseases of the central nervous system (Siegel and Khosla 2007). In addition, it has been identified as a target for therapeutic intervention (Pietsch et al. 2013). Presumably best understood is the role of TG2 in celiac disease, where open conformation TG2 mediates the deamidation of dietary gluten peptides via a gluten peptide-TG2 thioester intermediate, resulting in T-cell activation and inflammatory processes (Klöck et al. 2012). In kidney, liver and lung fibrotic diseases, TG2 is suspected to increasingly crosslink extracellular matrix proteins, directly producing scar tissue (Grenard et al. 2001; Johnson et al. 1997; Olsen et al. 2011). linking activity, whereas extracellularly, the high calcium 
In oncology, the role of TG2 is more ambiguous, with either protective anti-apoptotic and pro-apoptotic functions being described (Kotsakis and Griffin 2007). TG2 upregulation has been associated with increased metastasis of various tumour cell lines (Mehta et al. 2004; Satpathy et al. 2007) and drug resistance (Kumar et al. 2010) by promoting epithelial-tomesenchymal transition, independent of cross-linking activity. In addition, upregulation of the pro-survival transcription factor NF- $\mathrm{kB}$ may play a role in drug resistance (Brown 2013), by TG2-mediated cross-linking and deactivation of NF-кB's endogenous inhibitor I $\mathrm{B} \alpha$. The TG2 cross-linking dependency remains questionable (Brown 2013). In neurodegenerative diseases, TG2 cross-linking of well-known disease specific proteins, such as amyloid $\beta$, huntingtin, and tau, has been associated with the formation of stable neurotoxic aggregates (Wilhelmus et al. 2008).

However, because of its presence in multiple cellular compartments as well as outside the cell (Slife et al. 1985; Lesort et al. 1998), its multiple conformations (Liu et al. 2002; Pinkas et al. 2007), and functions (Gundemir et al. 2012), intrinsically TG2 is a difficult protein to study in vivo. The development of PET tracers for imaging of TG2 activity in vivo may lead to a better understanding of the role of this interesting protein in disease. This review illustrates the potential strategies for TG2 PET imaging and describes potent lead compounds within the context of potential translation to TG2 PET tracers.

\section{General}

This review will focus on compounds with high potential that justify further elaboration and compounds from different compound classes that allow for different imaging strategies (Figs. 2, 3). As the acyl transfer mechanism of TG2 follows a double displacement reaction (Keillor et al. 2014), various enzymatic states may be intercepted with a PET imaging agent (Fig. 2). In the closed conformation (Fig. 2a), TG2 may be targeted by antibodies or by small organic molecules at the GTP-binding domain. Besides targeting with antibodies, the open conformation (Fig. 2b) may bind to radiolabelled reversible and irreversible TG2 inhibitors, as well as acyl-donor substrates. Finally, the intermediate thioester between TG2 and the acyl-donor may be intercepted by radiolabelled acyl-acceptor substrates (Fig. 2c). Chemical structures of small molecule compounds described in this review are depicted in Fig. 3.

\section{Irreversible inhibitors}

The majority of previously proposed potent TG2 inhibitors are irreversible inhibitors, with recurring moieties, such as diazoketones, $\alpha$-haloketones, dialkylsulfonium salts, 3-halo-4,5-dihydroxyisoxazoles, and acryl amides or related Michael acceptors (Keillor et al. 2015). The use of PET labelled irreversible TG2 inhibitors should, provided that the newly formed covalent bond is, indeed, irreversible, lead to accumulation of the radiotracer in regions with high-local TG2 cross-linking activity. The first radiolabelled irreversible transglutaminase inhibitor (Freund et al. 1994) was based on the class of imidazole derivatives. By designing two carbon-14 (not a PET isotope) labelled regioisomers of the non-selective inhibitor 1,3-dimethyl-2[(2-oxopropyl)thio]imidazolium chloride (NTU283 in Fig. 3), the mechanism of transglutaminase inhibition was confirmed as active-site cysteine acetonylation, with the imidazole moiety as leaving group (Freund et al. 1994). Therefore, straightforward carbon-11 methylation on the imidazole moiety of a desmethyl precursor would result in labelling of the leaving imidazole group which would not be retained in tissue, but rather be cleared from the original reaction site. Carbon-11 labelling of the acetonyl functionality is not feasible using the currently available radiochemical toolbox. Analogues of this inhibitor bearing a fluorine-18 atom on the acetonyl group might be developed. NTU283, however, suffers from low potency and comparable affinity towards the transglutaminase FXIIIa (Griffin et al. 2008; Freund et al. 1994).

More potent and selective irreversible TG2 inhibitors carrying an acrylamide moiety have recently been reported (1-3 in Fig. 3) (Prime et al. 2012a, b; Wityak et al. 2012). Conveniently, carbon-11 radiosynthesis of acryl amides has been reported using various strategies resulting in the carbon-11 atom at the acrylamide carbonyl position, rendering this class of Michael acceptor inhibitors amenable to radiolabelling (Eriksson et al. 2007). The most convenient amongst these synthetic strategies is the palladiummediated one-pot $\left[{ }^{11} \mathrm{C}\right] \mathrm{CO}$ aminocarbonylation method. In fact, recently, the carbon-11 radiosynthesis together with the evaluation of three potent irreversible TG2 inhibitors radiolabelled using this methodology was described (Van der Wildt et al. 2016). In healthy rodents, however, these compounds displayed low metabolic stability at tracer concentrations, with biological half-lives below $45 \mathrm{~min}$. After selecting the most stable of these three compounds, i.e., compound $\left[{ }^{11} \mathrm{C}\right] 3$ (Fig. 3), autoradiography experiments on MDA-MB-231 tumour sections, known for its high expression of TG2 (Mehta et al. 2004), demonstrated selective and specific binding to TG2 (Van der Wildt et al. 2016). Nevertheless, TG2-targeting potential of this compound in vivo still remains to be established. Other potent acrylamide inhibitors based on an aminopiperidine core have been reported. Apart from $\left[{ }^{11} \mathrm{C}\right] \mathrm{CO}$ aminocarbonylation, the strongest inhibitor within this class, compound $\mathbf{9 q}$, potentially allows for radiolabelling at the methoxy 
Irreversible inhibitors<smiles>CC(=O)CSc1n(C)cc[n+]1C</smiles>

NTU283

$\mathrm{IC}_{50}: 4 \mu \mathrm{M}$<smiles>C=CC(=O)Nc1ccc(S(=O)(=O)N2CCN(C(=O)C34CC5CC(CC(C5)C3)C4)CC2)cc1</smiles>

$\mathrm{IC}_{50}: 10 \mathrm{nM}$<smiles>C=CC(=O)NCCCC[C@H](NC(=O)OCc1ccccc1)C(=O)N1CCN(c2ccccc2Cl)CC1</smiles>

$\mathrm{IC}_{50}: 62 \mathrm{nM}$<smiles>C=CC(=O)NCCCC[C@H](NC(=O)Cc1ccccc1)C(=O)N1CCN(c2cccc(C)n2)CC1</smiles>

$\mathrm{IC}_{50}: 14 \mathrm{nM}$

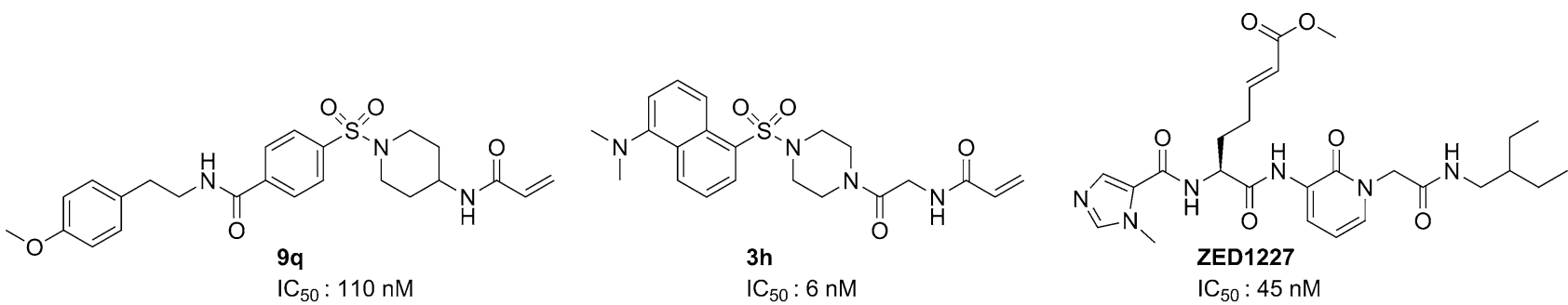<smiles>COC(=O)[C@H](CC(C)C)NC(=O)[C@@H]1CCCN1C(=O)[C@@H](NC(=O)[C@H](CCC(=O)C=N)NC(=O)CO/N=C/c1ccc(F)cc1)C(C)C</smiles>

$\mathrm{IC}_{50}: 72 \mathrm{nM}$<smiles>CCC(=O)N[C@@H](CCC(=O)C=[W])C(=O)N[C@H](C(=O)N1CCC[C@H]1C(=O)N[C@@H](CC(C)C)C(=O)OC)C(C)C</smiles><smiles>O=C(NCC1CC(Br)=NO1)[C@@H]1CC(F)CN1C(=O)OCc1cnc2ccccc2c1</smiles>

ERW1041e analogue 2a $k_{\text {inh }} / \mathrm{K}_{\mathrm{i}}: 20.9 \mathrm{mM}^{-1} \cdot \mathrm{min}^{-1}$

'Reversible' active site inhibitors<smiles>CC(C)N(CCC(=O)c1ccc2ccccc2c1)Cc1ccccc1</smiles>

ZM39923

$\mathrm{IC}_{50}: 10 \mathrm{nM}$<smiles>C=CC(=O)c1ccc2ccccc2c1</smiles>

ZM449829

$\mathrm{IC}_{50}: 5 \mathrm{nM}$

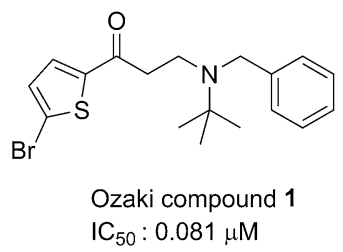

Acyl acceptor substrates<smiles>NCCCCCNC(=O)c1ccc(F)cc1</smiles>

$\left[{ }^{18} \mathrm{~F}\right]$ SFB-Cadaverine<smiles>O=C(/C=C/c1ccc([N+](=O)[O-])cc1)c1cn(Cc2ccc([N+](=O)[O-])cc2)nn1</smiles>

$\mathrm{IC}_{50}: 2.1 \mu \mathrm{M}$

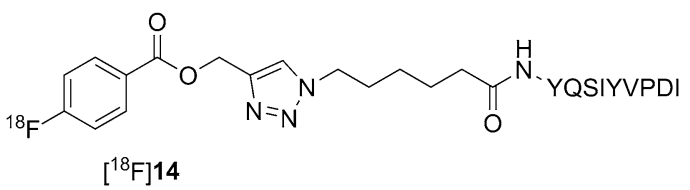
$\left[{ }^{18} \mathrm{~F}\right] 14$

GTP site binders<smiles>NNC(=O)CSc1nc2sc(Cl)c(-c3ccccc3F)c2c(=O)n1-c1cccc(F)c1</smiles>

LDDN-80042

$\mathrm{IC}_{50}: 0.13 \mu \mathrm{M}$

Fig. 3 Radiolabelled TG2 inhibitors, substrates, and other compounds that may be suited as lead compounds for the development of TG2 PET imaging agents and as such are discussed in this review. The position of the carbon-11 label in compound $\left[{ }^{11} \mathrm{C}\right] \mathbf{1}-\left[{ }^{11} \mathrm{C}\right] \mathbf{3}$ is depicted with asterisk

position by straightforward $\left[{ }^{11} \mathrm{C}\right] \mathrm{MeI}$ methylation of the corresponding O-desmethyl precursor (Prime et al. 2012b). Recently, Badarau et al. also reported on the development of potent TG2 inhibitors carrying the acrylamide moiety (Badarau et al. 2015). Unfortunately, the most potent compound $\mathbf{3 h}$, which is the strongest irreversible inhibitor reported to date, showed low microsomal stability. Compound $\mathbf{3 h}$, however, did show potency in vivo in a hypertensive nephropathy model, using local administration of $\mathbf{3 h}$ by constant infusion. As for compound $\mathbf{9 q}$, carbon-11 
radiolabelling of $\mathbf{3 h}$ might be performed by aminocarbonylation or $N$-methylation of the $N$-desmethyl precursor. Zedira $\mathrm{GmbH}$ has reported the start of Phase I trials using their compound ZED1227, a promising peptidomimetic irreversible inhibitor carrying a Michael acceptor other than acrylamide [Zedira GmbH patent filing WO2014012858 (A1), 2014]. This compound is accessible for carbon-11 methylation at either of two methyl groups.

Z006 (Z-DON-Val-Pro-Leu-OMe) is a highly potent and selective peptidic inhibitor of TG2 (Verhaar et al. 2011; Schaertl et al. 2010). Theoretically, Z006 allows for radiolabelling at the C-terminal methyl ester employing either $\left[{ }^{11} \mathrm{C}\right] \mathrm{MeI}$ or $\left[{ }^{11} \mathrm{C}\right] \mathrm{CH}_{2} \mathrm{~N}_{2}$. Methylesters, however, are not very stable in vivo, and, therefore, are rarely the preferred site of introduction of the PET label. Recently, radiosynthesis and preliminary in vivo evaluation of fluorine-18 labelled analogues of $\mathbf{Z 0 0 6}$ have been reported ( $\left[{ }^{18} \mathrm{~F}\right] \mathbf{t T G}$ 036 and $\left[{ }^{18} \mathrm{~F}\right]$ tTG-038 in Fig. 3) (Van der Wildt et al. 2013, 2015). As expected, the methyl ester on $\left[{ }^{18} \mathrm{~F}\right] \mathbf{t T G}-\mathbf{0 3 8}$ appeared to be metabolically unstable in vivo. Interestingly, however, the resulting carboxylic acid was demonstrated to be metabolically stable and an active TG2 inhibitor as well. Together, these results merit further evaluation of $\left[{ }^{18} \mathrm{~F}\right] \mathbf{t T G}-038$ in vivo. ERW1041E (DiRaimondo et al. 2013) was shown to prevent BAP incorporation in a pulmonary hypertension mouse model following intraperitoneal administration. This work concludes that a longitudinal TG2 activity study in PH patients is warranted to confirm TG2 as a biomarker for this disease, emphasizing the necessity for a TG2 PET tracer. To allow radiolabelling, equipotent analogues of ERW1041E that are accessible for fluorine-18 labelling were designed as putative future TG2 PET tracers (ERW1041E analogue 2a in Fig. 3). Although ERW1041E has shown in vivo inhibition of TG2 activity in this mouse model at $50 \mathrm{mg} \mathrm{kg}^{-1}$, it still remains to be elucidated whether this compound class will prove valuable at tracer concentrations. Furthermore, in the previous research, analogues of ERW1041E were not able to inhibit TG2 cross-linking activity in an intestinal inflammation model despite various ways of inhibitor administration (Siegel et al. 2008).

\section{Reversible active-site inhibitors}

Binding potential, which reflects $B_{\max } / K_{\mathrm{d}}$, is a key predictor of the potency of a reversible radiopharmaceutical for imaging a given target [Eckelman and Mathis 2006]. Highaffinity compounds are thus preferred, especially if target expression is low. Because little is known about $B_{\max }$ for TG2 in physiological and diseased states, high-affinity compounds should be selected as starting point for PET tracer development. To date, in contrast to irreversible
TG2 inhibitors, only few reversible inhibitors with $\mathrm{IC}_{50}$ 's in the two digit nanomolar range have been reported. Following screening of an existing drug library, the Janus kinase inhibitor ZM39923 and its 'metabolite' ZM449829 (Brown et al. 2000; Lai et al. 2008) were reported as potent TG2 inhibitors with 10 and $5 \mathrm{nM} \mathrm{IC}_{50}$ 's, respectively. Carbon-11 labelling of ZM39923 should be feasible by a reductive amination reaction between amine precursor and $\left[{ }^{11} \mathrm{C}\right]$ acetone (Berridge et al. 1992) or by alkylation of the corresponding precursor with $\left[{ }^{11} \mathrm{C}\right]$ benzyl iodide (Pekošak et al. 2015). Including $10 \mathrm{mM}$ DTT in the incubation solution, however, resulted in a drastic increase in $\mathrm{IC}_{50}$ to micromolar values for both inhibitors (Lai et al. 2008). These $\mathrm{IC}_{50}$ values corresponded with those reported in a later study (Schaertl et al. 2010). Although the provided explanation for this phenomenon included, besides an 'unknown complex mechanism of inhibition' involvement of these inhibitors in promoting disulfide bonds and thus inactivating the enzyme (Lai et al. 2008), it appears more likely that ZM39923 is converted to the actual TG2 inhibitor ZM449829 by a retro Michael reaction (Brown et al. 2000). Using similar assay conditions, i.e., PBS solution, rapid conversion of ZM39923 to ZM449829 has already been observed. This newly formed Michael acceptor compound ZM449829, in turn, is responsible for irreversible TG2 inhibition. The subsequent cross-reactivity of ZM449829 towards DTT, as a thiol competing with the active-site cysteine residue, results in a loss of TG2 inhibition. Radiolabelling of $\mathbf{Z M 4 4 9 8 2 9}$ could be achieved on the carbonyl position by a Suzuki or Stille $\left[{ }^{11} \mathrm{C}\right] \mathrm{CO}$ insertion reaction (Nader and Oberdorfer 2002). However, the putative cross-reactivity with various thiols will likely limit the chance of successful in vivo TG2 imaging using either $\left[{ }^{11} \mathrm{C}\right] \mathbf{Z M 3 9 9 2 3}$ or $\left[{ }^{11} \mathrm{C}\right] \mathbf{Z M 4 4 9 8 2 9}$. Ozaki et al. also reported on $\beta$-aminoketone structures, such as ZM39923, as potent active-site TG2 inhibitors (Ozaki et al. 2010). Their most promising compound 1 (Fig. 3) allows for carbon-11 radiolabelling at the tert-butyl (Elsinga et al. 1995) or, like ZM39923, at the benzyl functionality (Pekošak et al. 2015). It is conceivable, however, that Ozaki compound $\mathbf{1}$ also acts as a prodrug that via retro Michael reaction converts to an active inhibitor, given the structural similarities to ZM39923. No stability data for the developed compounds were provided, nor selectivity data towards other transglutaminases or biological reactive thiols (e.g., glutathione, caspase). In addition, no DTT was used in their assay. Together, it is possible that their reversible inhibitors are actually prodrugs for non-selective irreversible TG2 inhibitors (Ozaki et al. 2010) following a similar mechanism as for compound ZM449829. Another class of reported reversible inhibitors is the cinnamoyl-based inhibitors, such as CP4d (Fig. 3) (Pardin et al. 2008a, b). Potency of these compounds, however, is limited, hampering their 
use as lead compound for PET tracer development (Fig. 3, reported $\mathrm{IC}_{50}: 2.1 \mu \mathrm{M} ; K_{i}: 174 \mathrm{nM}$ ). In addition to the low affinity, although being reported as a reversible inhibitor competitive with the acyl-donor substrate, this compound class could potentially react as irreversible inhibitors. The thiol-reactive Michael acceptor motif is present in the cinnamoyl structure (Esterbauer et al. 1975) and has been shown in related structures to react with biologically active thiols, as present in transglutaminases (Schwöbel et al. 2010). The selectivity data of these compounds towards transglutaminase FXIIIa and cysteineprotease caspase 3 , although seemingly promising, are biased by the presence of DTT in these counter assays (Pardin et al. 2008a). DTT, omitted in the TG2 inhibition assay, could very well be acting as a competitive nucleophile for cinnamoyl-based inhibitors and thus preventing FXIIIa and caspase 3 inhibition, suggesting selectivity. The putative irreversible inhibition of these compounds is further encouraged by the fact that modifications at the $\alpha, \beta$-unsaturated ketone motif, losing the Michael acceptor reactivity, results in complete loss of potency (Pardin et al. 2008a). Finally, a recent study discussing the reactivity between biological thiols and cinnamoyl-coumarin constructs showed that cinnamoyl compounds with the highest Michael acceptor reactivity carried a $p$-nitrophenyl group, conjugated to the $\alpha, \beta$-unsaturated ketone, a structure that is sharing high structural similarities with structure CP4d (Aliaga et al. 2014). Therefore, it is highly desirable to evaluate the stability of the inhibitors mentioned above in the presence of thiols and to perform TG2 inhibition experiments in the presence of competing thiols (DTT). These experiments might result in re-evaluation of the exact binding mode of this class of compounds (Pardin et al. 2009).

In summary, it seems that at present, no reversible active-site inhibitors for TG2 with low nanomolar affinities are available. Furthermore, cross-reactivity of irreversible inhibitors, although, perhaps, also for reversible inhibitors, towards thiols (e.g. glutathione, DTT) should be carefully determined prior to starting elaborate SAR studies to avoid false positive in vitro inhibition results.

\section{GTP-binding site inhibitors}

Orthosteric GTP-binding site inhibitors of TG2 as well as inhibitors with unknown binding sites that inhibit GTPbinding have been described (Lai et al. 1998; Duval et al. 2005). Other than GTP itself or closely related analogues, such as dGTP-, GTP $\gamma \mathrm{S}-$, or Bopdipy-modified GTP $\gamma \mathrm{S}$ (Datta et al. 2006), no structurally distinct orthosteric inhibitors have been reported, suggesting the GTP-binding site to be highly specialized in this particular binding (Schaertl et al. 2010). In addition, the fact that GTP-binding domains are present in all G-proteins likely discards the GTP-binding site as suitable target for PET radiotracer development, as selectivity issues will arise. In contrast, it has been suggested that the class of hydrazine inhibitors prevents TG2 cross-linking activity by binding allosterically to the GTPbinding site and to multiple enzyme conformers (Duval et al. 2005; Case and Stein 2007; Schaertl et al. 2010). However, due to slow-binding kinetics, sub-optimal affinity, and unknown binding mechanism, PET tracer development based on this hydrazine scaffold appears not to be an attractive strategy.

\section{Acyl-acceptor substrates}

Carbon-14 radiolabelled acyl-acceptor substrates have been at the heart of transglutaminase discovery in the late 1950s, when it was found that liver-derived protein extracts were responsible for amine incorporation into proteins (Sarkar et al. 1957). An important advantage of labelled substrates over inhibitors is the potential signal magnification by means of catabolic trapping, as multiple substrates per transglutaminase enzyme can be incorporated into the local tissue, whereas inhibitors can maximally bind at a 1:1 ratio with the transglutaminase enzyme. Acyl-acceptor substrates for TG2 differ from acyl-donor substrates or activesite inhibitors in that they do not bind to the enzyme itself, but rather compete with naturally present amines, or water, for interception of the intermediate thioester between enzyme and acyl-donor substrate. In contrast to the first step in the cross-linking reaction, the nucleophilic attack on the thioester is not selective (Keillor et al. 2014). In addition, processing of amines in vivo is not limited to TG2, as other transglutaminases as well as other enzymes have amines as substrates. Together, the lack of selectivity of acyl-acceptor substrates will likely hamper the success of this approach towards TG2 PET imaging agents. Nonetheless, TG2-mediated incorporation of the substrate BAP was demonstrated ex vivo in lung tissue using a mouse model of hypoxia-induced pulmonary hypertension (DiRaimondo et al. 2013). In such an ex vivo approach, selectivity data are obtained by pre-treatment of test animals with a TG2 inhibitor after which the free amine substrate is removed by thoroughly washing the tissue sections. In the case of in vivo PET imaging, removal of free ligand by sequential washing procedures is impossible, potentially resulting in a much lower specific signal. Nevertheless, two research groups have reported preliminary results on the fluorine-18 labelling of polyamines, such as putresceine, spermidine, or cadaverine using $\left[{ }^{18} \mathrm{~F}\right] \mathrm{SFB}$ as amine reactive prosthetic group (Wodtke et al. 2013; Ackermann et al. 2014). In a small pilot experiment using SK-RC-52 tumour bearing mice, a high tumour to blood activity ratio of $\left[{ }^{18} \mathrm{~F}\right]$ 
fluorobenzamide-cadaverine was obtained (Ackermann et al. 2014). Whether this signal was TG2 mediated, however, remains to be elucidated, but it is likely that more in vivo imaging results will be published in the near future.

\section{Acyl-donor substrates}

Although various TG2 specific acyl-donor substrates have been developed for measuring TG2 activity in vitro (Pietsch et al. 2013), to the best of our knowledge, no reports have described ex vivo or in vivo use of radiolabelled acyl-donor substrates for measuring TG2 cross-linking activity. One report has described the radiosynthesis of a fluorine-18 labelled acyl-donor substrate (Vaidyanathan et al. 2009). This fluorine-18 labelled TG2 specific substrate T32 was selected based on a phage-displayed peptide library screening (Sugimura et al. 2006). Unfortunately, the desired TG2 substrate, $\left[{ }^{18} \mathrm{~F}\right] \mathbf{1 4}$ was obtained with poor purity and was not formulated in a solution ready for injection. As a consequence, no in vivo work has been reported with this substrate. TG2-reactive peptide sequences should in vivo be incorporated in tissues with a high-local TG2 activity with the same potential signal magnification as described for acyl-acceptor substrates (vide supra). Such peptidic constructs often allow for $\mathrm{N}$-terminal modification to enable chemoselective reaction with a fluorine-18 building block or with a chelating moiety for incorporation of a radiometal of choice. Using a comparable approach, FXIIIa activity imaging has been attempted using ${ }^{99 \mathrm{~m}} \mathrm{Tc}$ - and ${ }^{111} \mathrm{In}$-labelled peptidic $\alpha 2$-antiplasmin regions, which were functioning as acyl-donor substrates (Edwards et al. 2006; Nahrendorf et al. 2006). The ${ }^{99 \mathrm{~m}} \mathrm{Tc}$ labelled construct showed high uptake in vitro in plasma clots and moderate uptake in vivo in rodent blood clots, which was determined ex vivo by means of a biodistribution experiment. Ex vivo, after thorough washing of the tissues, the ${ }^{111}$ In-labelled construct was shown to be selectively incorporated by FXIIIa in the infarct region in a mouse model of myocardial infarction. Unfortunately, no in vivo imaging was performed in either study. However, it seems likely that a similar strategy, when carefully selecting and developing a high-affinity peptide for TG2, could be used for imaging of extracellular TG2 activity in vivo.

\section{Antibodies}

PET imaging using radiolabelled antibodies, a technique commonly referred to as 'Immuno-PET' (Van Dongen et al. 2015), has shown to be well suited for imaging of extracellular targets, such as receptors, and other membrane bound proteins, such as enzymes and transporters. Furthermore, compared to small organic molecules, antibodies generally display less uptake in liver and kidneys and thus allow for PET imaging studies concerning pathologies of these specific organs (Grenard et al. 2001; Johnson et al. 1997). Since TG2 has two highly distinct conformations, the characteristics of the radiolabelled antibody, more precisely. the epitope to which the antibody is directed, will determine what will be measured. When interested in measuring TG2 expression, independent of conformation, the antibody might best be raised against any TG2 domain, though one must consider that extracellularly, the N-terminal domain is likely bound to fibronectin (Hang et al. 2005) and the C-terminal domain involved in integrin binding (Akimov et al. 2000), potentially hampering antibody accessibility. For measuring extracellular TG2 activity rather than expression, the specific antibody should be designed to bind selectively to the open conformation. It must be noted that this is the assumed extracellular conformation due to the $\mathrm{mM}$ calcium concentrations in the interstitial fluid (Király et al. 2009). As such, the core domain, including the catalytic cross-linking site, is likely the preferred targeted epitope, as this region is only accessible in the catalytically active open conformation. A TG2 transamidation inhibiting antibody D11D12 has been reported, (patent filing WO2013175229, 2013; Wang et al. 2013), although it has not been reported whether this antibody selectively binds to the open conformation. This TG2 antibody showed inhibition of TG2 transamidation-mediated angiogenesis and wound healing in cellular models (Wang et al., 2013) and further development might result in a huge step towards TG2 transamidation inhibition therapies. Furthermore, the well-known TG2 antibody CUB7402, amongst others, has shown TG2-inhibiting properties by preventing adhesion of Swiss 3T3 fibroblasts (Verderio et al. 1998), although CUB7402 TG2 transamidation inhibiting properties were lost when TG2 was preincubated with $\mathrm{Ca}^{2+}$ (Esposito et al. 2002), suggesting that CUB7402 does not bind to the open conformation of TG2, but to TG2 in a closed conformation. It is anticipated that 'TG2 Immuno-PET' will be a valuable tool in future research to increase understanding on TG2 biology.

\section{Future perspectives}

With several research groups reporting novel TG2 PET tracers in publications, conference abstracts, and annual reports, we are without any doubt at the frontier of in vivo TG2 PET imaging (Van der Wildt et al. 2013, 2015, 2016; Ackermann et al. 2014; Vaidyanathan et al. 2009), and there is no doubt that results from in vivo TG2 PET imaging studies in animal models of TG2 overexpression/overactivity will appear soon. Furthermore, highly potent small 
Table 1 Pro et contra of TG2 PET tracer development strategies as discussed in this review

\begin{tabular}{|c|c|c|c|c|c|}
\hline Irreversible inhibitors & Reversible inhibitors & $\begin{array}{l}\text { GTP-binding site } \\
\text { inhibitors }\end{array}$ & $\begin{array}{l}\text { Aryl-acceptor sub- } \\
\text { strates }\end{array}$ & Acyl-donor substrates & Antibodies \\
\hline \multicolumn{6}{|l|}{ Pro } \\
\hline High selectivity & High selectivity & $\begin{array}{l}\text { Potential imaging of } \\
\text { closed TG2 }\end{array}$ & Signal magnification & Signal magnification & $\begin{array}{l}\text { Low uptake in kidney } \\
\text { and liver }\end{array}$ \\
\hline High-affinity & $\begin{array}{l}\text { Potentially BBB } \\
\text { permeable }\end{array}$ & & & Selective & Long circulation \\
\hline $\begin{array}{l}\text { Potentially BBB } \\
\text { permeable }\end{array}$ & $\begin{array}{l}\text { Only cross-linking } \\
\text { active TG2 }\end{array}$ & & & $\begin{array}{l}\text { Only cross-linking } \\
\text { active TG2 }\end{array}$ & High selectivity \\
\hline $\begin{array}{l}\text { Only cross-linking } \\
\text { active TG2 }\end{array}$ & $\begin{array}{l}\text { Allow for pulse-chase } \\
\text { experiments }\end{array}$ & & & & High-affinity \\
\hline \multicolumn{6}{|l|}{ Contra } \\
\hline \multirow[t]{5}{*}{$\begin{array}{l}\text { High liver and kid- } \\
\text { ney uptake }\end{array}$} & Potency sub-optimal & $\begin{array}{l}\text { Competing with } \\
\text { endogenous GDP }\end{array}$ & Non-selective & Non-BBB permeable & Expression vs activity \\
\hline & $\begin{array}{l}\text { High liver and kidney } \\
\text { uptake }\end{array}$ & Low potency & & & Non-BBB permeable \\
\hline & & $\begin{array}{l}\text { Independent of cross- } \\
\text { linking activity }\end{array}$ & & & \\
\hline & & Poor cell penetration & & & \\
\hline & & Non-selective & & & \\
\hline
\end{tabular}

molecule inhibitors are continuously being developed at multiple academic and industrial institutes, increasing the options on lead compound selection for PET radiochemists (Keillor et al. 2015). Table 1 depicts the advantages and disadvantages of potential strategies for TG2 PET radiotracer development.

At present, the use of irreversible TG2 inhibitors appears to be an attractive strategy. In particular, irreversible acrylamide inhibitors readily allow for radiolabelling with carbon-11 and can thus be readily evaluated in vivo (Eriksson et al. 2007; Van der Wildt et al. 2016). Labelled acyl-donor substrates, successfully applied for ex vivo measurements of FXIIIa activity (Nahrendorf et al. 2006; Edwards et al. 2006), could also be applicable for imaging of TG2 crosslinking activity. Furthermore, TG2-inhibiting antibodies have been developed that might, unlike small molecules, allow for TG2 imaging in kidney and liver pathologies (Wang et al. 2013). Whether the radiolabelled antibody will reflect local open, closed, or both conformations of TG2 will fully depend on the antibody characteristics. Taken together, it is anticipated that PET will play an important role in moving in vitro and ex vivo biology findings on TG2 into mammalian in vivo studies. As such, it could play a pivotal role in monitoring of target engagement in TG2 drug development.

\section{Compliance with ethical standards}

Conflict of interest The authors declare that they have no conflict of interest.
Research involving human participants and/or animals This is a review article and it does not include animal or human participants.

Open Access This article is distributed under the terms of the Creative Commons Attribution 4.0 International License (http://creativecommons.org/licenses/by/4.0/), which permits unrestricted use, distribution, and reproduction in any medium, provided you give appropriate credit to the original author(s) and the source, provide a link to the Creative Commons license, and indicate if changes were made.

\section{References}

Ackermann U, Rigopoulos A, O'Keefe G et al (2014) Imaging of tissue transglutaminase activity in SK-RC-52 tumors. Austin LifeSciences Research Week, 216

Akimov SS, Krylov D, Fleischman LF et al (2000) Tissue transglutaminase is an integrin-binding adhesion coreceptor for fibronectin. J Cell Biol 148:825-838

Aliaga ME, Tiznado W, Cassels BK et al (2014) Substituent effects on reactivity of 3-cinnamoylcoumarins with thiols of biological interest. RSC Adv 4:697-704

Antonyak MA, Li B, Regan AD et al (2009) Tissue transglutaminase is an essential participant in the epidermal growth factor-stimulated signaling pathway leading to cancer cell migration and invasion. J Biol Chem 284:17914-17925

Badarau E, Wang Z, Rathbone DL et al (2015) Development of potent and selective tissue transglutaminase inhibitors: their effect on TG2 function and application in pathological conditions. Chem Biol 22:1347-1361

Bergström M, Grahnén A, Långström B (2003) Positron emission tomography microdosing: a new concept with application in tracer and early clinical drug development. Eur J Clin Pharmacol 59:357-366 
Berridge MS, Cassidy EH, Terris AH et al (1992) Preparation and in vivo binding $\left[{ }^{11} \mathrm{C}\right]$ carazolol, a radiotracer for beta-adrenergic receptor. Nucl Med Biol 19:563-569

Brown KD (2013) Transglutaminase 2 and NF-кB: an odd couple that shapes breast cancer phenotype. Breast Cancer Res Treat 137:329-336

Brown GR, Bamford AM, Bowyer J et al (2000) Naphthyl ketones: a new class of Janus kinase 3 inhibitors. Bioorg Med Chem Lett 10:575-579

Case A, Stein RL (2007) Kinetic analysis of the interaction of tissue transglutaminase with a nonpeptidic slow-binding inhibitor. Biochemistry 46:1106-1115

Czernin J, Phelps ME (2002) Positron emission tomography scanning: current and future applications. Ann Rev Med 53:89-112

Datta A, Antonyak MA, Cerione RA (2006) Importance of $\mathrm{Ca}^{2+}$ dependent transamidation activity in the protection afforded by tissue transglutaminase against doxorubicin-induced apoptosis. Biochemistry 45:13163-13174

DiRaimondo TR, Klöck C, Warburton R et al (2013) Elevated transglutaminase 2 activity is associated with hypoxia-induced experimental pulmonary hypertension in mice. ACS Chem Biol 9:266-275

Duval E, Case A, Stein RL et al (2005) Structure-activity relationship study of novel tissue transglutaminase inhibitors. Bioorg Med Chem Lett 15:1885-1889

Eckelman WC, Mathis CA (2006) Targeting proteins in vivo: in vitro guidelines. Nucl Med Biol 33:161-164

Edwards D, Lewis J, Battle M et al (2006) ${ }^{99 \mathrm{~m}} \mathrm{Tc}-\mathrm{NC} 100668$, a new tracer for imaging venous thromboemboli: pre-clinical biodistribution and incorporation into plasma clots in vivo and in vitro. Eur J Nucl Med Mol Imaging 33:1258-1265

Elsinga PH, Keller E, De Groot TJ et al (1995) Synthesis of $\left[{ }^{11} \mathrm{C}\right]$ methyl magnesium iodide and its application to the introduction of $\left[{ }^{11} \mathrm{C}\right]-\mathrm{N}$-tert-butyl groups and $\left[{ }^{11} \mathrm{C}\right]$-sec-alcohols. Appl Radiat Isot 46:227-231

Eriksson J, Åberg O, Långström B (2007) Synthesis of $\left[{ }^{11} \mathrm{C}\right] /\left[{ }^{13} \mathrm{C}\right]$ acrylamides by palladium-mediated carbonylation. Eur $\mathrm{J}$ Org Chem 2007:455-461

Esposito C, Paparo F, Caputo I et al (2002) Anti-tissue transglutaminase antibodies from coeliac patients inhibit transglutaminase activity both in vitro and in situ. Gut 51:177-181

Esterbauer H, Zollner H, Scholz N (1975) Reaction of glutathione with conjugated carbonyls. Z Naturforsch 30:466-473

Fésüs L, Szondy Z (2005) Transglutaminase 2 in the balance of cell death and survival. FEBS Lett 579:3297-3302

Freund KF, Doshi KP, Gaul SL et al (1994) Transglutaminase inhibition by 2-[(2-oxopropyl)thio]imidazolium derivatives: mechanism of factor XIIIa inactivation. Biochemistry 33:10109-10119

Grenard P, Bresson-Hadni S, El Alaoui S et al (2001) Transglutaminase-mediated cross-linking is involved in the stabilization of extracellular matrix in human liver fibrosis. J Hepatol 35:367-375

Griffin M, Casadio R, Bergamini CM (2002) Tranglutaminases: nature's biological glues. Biochem J 368:377-396

Griffin M, Mongeot A, Collighan R et al (2008) Synthesis of potent water-soluble tissue transglutaminase inhibitors. Bioorg Med Chem Lett 18:5559-5562

Gundemir S, Colak G, Tucholski J et al (2012) Transglutaminase 2: a molecular Swiss army knife. Biochim Biophys Acta Mol Cell Res 1823:406-419

Hang J, Zemskov EA, Lorand L et al (2005) Identification of a novel recognition sequence for fibronectin within the $\mathrm{NH} 2$-terminal beta-sandwich domain of tissue transglutaminase. J Biol Chem 280:23675-23683

Im MJ, Russell MA, Feng JF (1997) Transglutaminase II: a new class of GTP binding protein with new biological functions. Cell Signal 9:477-482
Johnson TS, Griffin M, Thomas GL et al (1997) The role of transglutaminase in the rat subtotal nephrectomy model of renal fibrosis. J Clin Invest 99:2950-2960

Jones T, Rabiner EA (2012) The development, past achievements, and future directions of brain PET. J Cereb Blood Flow Metab 32:1426-1454

Keillor JW, Clouthier CM, Apperley KYP et al (2014) Acyl transfer mechanisms of tissue transglutaminase. Bioorg Chem 57:186-197

Keillor JW, Apperley KY, Akbar A (2015) Inhibitors of tissue transglutaminase. Trends Pharmacol Sci 36:32-40

Király R, Csősz E, Kurtán T et al (2009) Functional significance of five noncanonical $\mathrm{Ca}^{2+}$-binding sites of human transglutaminase 2 characterized by site-directed mutagenesis. FEBS J 276:7083-7096

Klöck C, DiRaimondo TR, Khosla C (2012) Role of transglutaminase 2 in celiac disease pathogenesis. Semin Immunopathol 34:513-522

Kotsakis P, Griffin M (2007) Tissue transglutaminase in tumour progression: friend or foe? Amino Acids 33:373-384

Kumar A, Xu J, Brady S et al (2010) Tissue transglutaminase promotes drug resistance and invasion by inducing mesenchymal transition in mammary epithelial cells. PLoS One 5:e13390

Lai TS, Bielawska A, Peoples KA et al (1997) Sphingosylphosphocholine reduces the calcium ion requirement for activating tissue transglutaminase. J Biol Chem 272:16295-16300

Lai TS, Slaughter TF, Peoples KA et al (1998) Regulation of human tissue transglutaminase function by magnesium-nucleotide complexes. Identification of distinct binding sites for Mg-GTP and Mg-ATP. J Biol Chem 273:1776-1781

Lai TS, Liu Y, Tucker T et al (2008) Identification of chemical inhibitors to human tissue transglutaminase by screening existing drug libraries. Chem Biol 15:969-978

Lesort M, Attanavanich K, Zhang J et al (1998) Distinct nuclear localization and activity of tissue transglutaminase. J Biol Chem 273:11991-11994

Liu S, Cerione RA, Clardy J (2002) Structural basis for the guanine nucleotide-binding activity of tissue transglutaminase and its regulation of transamidation activity. PNAS 99:2743-2747

Ma Y, Kiesewetter DO, Lang L et al (2010) Applications of LC-MS in PET radioligand development and metabolic elucidation. Curr Drug Metab 11:483-493

Medical Research Council Technology, Johnson TM, Watson P, Matthews D et al (2013) Anti-transglutaminase 2 antibodies, WO2013175229 (A1)

Mehta K, Fok J, Miller FR et al (2004) Prognostic significance of tissue transglutaminase in drug resistant and metastatic breast cancer. Clin Cancer Res 10:8068-8076

Miller PW, Long NJ, Vilar R et al (2008) Synthesis of ${ }^{11} \mathrm{C},{ }^{18} \mathrm{~F},{ }^{15} \mathrm{O}$, and ${ }^{13} \mathrm{~N}$ radiolabels for positron emission tomography. Angew Chem Int Ed 47:8998-9033

Nader MW, Oberdorfer F (2002) Syntheses of [carbonyl- $\left.{ }^{11} \mathrm{C}\right] 2-$ (2-benzoylphenoxy)- $N$-phenylacetamide from $\left[{ }^{11} \mathrm{C}\right]$ carbon monoxide by the Suzuki and the Stille reactions. Appl Radiat Isot 57:681-685

Nahrendorf M, Hu K, Frantz S et al (2006) Factor XIII deficiency causes cardiac rupture, impairs wound healing, and aggravates cardiac remodeling in mice with myocardial infarction. Circulation 113:1196-1202

Olsen KC, Sapinoro RE, Kottmann RM (2011) Transglutaminase 2 and its role in pulmonary fibrosis. Am J Respir Crit Care Med 184:699-707

Ozaki S, Ebisui E, Hamada K et al (2010) Potent transglutaminase inhibitors, aryl $\beta$-aminoethyl ketones. Bioorg Med Chem Lett 20:1141-1144

Pardin C, Pelletier JN, Lubell WD et al (2008a) Cinnamoyl inhibitors of tissue transglutaminase. J Org Chem 73:5766-5775 
Pardin C, Roy I, Lubell WD et al (2008b) Reversible and competitive cinnamoyl triazole inhibitors of tissue transglutaminase. Chem Biol Drug Des 72:189-196

Pardin C, Roy I, Chica RA (2009) Photolabeling of tissue transglutaminase reveals the binding mode of potent cinnamoyl inhibitors. Biochemistry 48:3346-3353

Pekošak A, Filp U, Rotteveel L et al (2015) Improved synthesis and application of $\left[{ }^{11} \mathrm{C}\right]$ benzyl iodide in positron emission tomography radiotracer production. J Labell Compd Radiopharm 58:342-348

Phelps ME (2000) Positron emission tomography provides molecular imaging of biological processes. Proc Natl Acad Sci USA 97:9226-9233

Pietsch M, Wodtke R, Pietzsch J et al (2013) Tissue transglutaminase: an emerging target for therapy and imaging. Bioorg Med Chem Lett 23:6528-6543

Pike VW (2009) PET Radiotracers: crossing the blood-brain barrier and surviving metabolism. Trends Pharmacol Sci 30:431-440

Pinkas DM, Strop P, Brunger AT, Khosla C (2007) Transglutaminase 2 undergoes a large conformational change upon activation. PLoS Biol 5:2788-2796

Prime ME, Andersen OA, Barker JJ et al (2012a) Discovery and structure-activity relationship of potent and selective covalent inhibitors of transglutaminase 2 for Huntington's disease. J Med Chem 55:1021-1046

Prime ME, Brookfield FA, Courtney SM et al (2012b) Irreversible 4-aminopiperidine transglutaminase 2 inhibitors for Huntington's disease. ACS Med Chem Lett 3:731-735

Santhanam L, Tuday EC, Webb AK et al (2010) Decreased S-nitrosylation of tissue transglutaminase by endothelial nitric oxide synthase contributes to age-related increases in vascular stiffness. Circ Res 107:117-125

Sarkar NK, Clarke DD, Waelsch H (1957) An enzymetically catalyzed incorporation of amines into proteins. Biochim Biophys Acta 25:451-452

Satpathy M, Cao L, Pincheira R et al (2007) Enhanced peritoneal ovarian tumor dissemination by tissue transglutaminase. Cancer Res 67:7194-7202

Schaertl S, Prime M, Wityak J et al (2010) A profiling platform for the characterization of transglutaminase 2 (TG2) inhibitors. J Biomol Screen 15:478-487

Schwöbel JAH, Wondrousch D, Koleva YK et al (2010) Prediction of Michael type acceptor reactivity toward glutathione. Chem Res Toxicol 23:1576-1585

Siegel M, Khosla C (2007) Transglutaminase 2 inhibitors and their therapeutic role in disease states. Pharmacol Ther 115:232-245

Siegel M, Strnad P, Watts RE et al (2008) Extracellular transglutaminase 2 is catalytically inactive, but is transiently activated upon tissue injury. PLoS One 3:e1861

Singh US, Kunar MT, Kao YL et al (2001) Role of transglutaminase II in retinoic acid-induced activation of RhoA-associated kinase-2. EMBO J 20:2413-2423

Slife CW, Dorsett MD, Bouquett GT et al (1985) Subcellular localization of a membrane-associated transglutaminase activity in rat liver. Arch Biochem Biophys 241:329-336

Stamnaes J, Pinkas DM, Fleckenstein B et al (2010) Redox regulation of transglutaminase 2 activity. J Biol Chem 285:25402-25409

Sugimura Y, Hosono M, Wada F et al (2006) Screening for the preferred substrate sequence of transglutaminase using a phagedisplayed peptide library: identification of peptide substrates for TGase 2 and factor XIIIa. J Biol Chem 281:17699-17706
Vaidyanathan G, White BJ, Zalutsky MR (2009) Propargyl 4- $\left[{ }^{18} \mathrm{~F}\right]$ fluorobenzoate: a putatively more stable prosthetic group for the fluorine-18 labeling of biomolecules via click chemistry. Curr Radiopharm 2:63-74

Van der Wildt B, Drukarch B, Jongelen CAM et al (2013) Labeling of a tissue transglutaminase inhibitor. J Labell Compd Radiopharm $56: \mathrm{S} 342$

Van der Wildt B, Drukarch B, Kooijman EJ et al (2015) Development of peptidic fluorine-18 labeled PET tracers for in vivo determination of tissue transglutaminase activity. J Label Compd Radiopharm 58:S203

Van der Wildt B, Wilhelmus MMM, Bijkerk J et al (2016) Development of carbon-11 labeled acryl amides for selective PET imaging of active tissue transglutaminase. Nucl Med Biol 43:232-242

Van Dongen GAMS, Visser GWM, Lub-de Hooge MN et al (2007) Immuno-PET: a navigator in monoclonal antibody development and applications. Oncologist 12:1379-1389

Van Dongen GAMS, Huisman MC, Boellaard R et al (2015) Zr89-immuno-PET for imaging of long circulating drugs and disease targets: why, how and when to be applied? Q J Nucl Med Mol Imaging 59:18-38

Verderio E, Nicholas B, Gross S et al (1998) Regulated expression of tissue transglutaminase in Swiss 3T3 fibroblasts: effects on the processing of fibronectin, cell attachment, and cell death. Exp Cell Res 239:119-138

Verhaar R, Jongenelen CAM, Gerard M et al (2011) Blockade of enzyme activity inhibits tissue transglutaminase-mediated transamidation of a-synuclein in a cellular model of Parkinson's disease. Neurochem Int 58:785-793

Vosjan MJWD, Perk LR, Visser GWM et al (2010) Conjugation and radiolabeling of monoclonal antibodies with zirconium-89 for PET imaging using the bifunctional chelate $p$-isothiocyanatobenzyl-desferrioxamine. Nat Protoc 5:739-743

Wang Z, Perez M, Caja S et al (2013) A novel extracellular role for tissue transglutaminase in matrix-bound VEGF-mediated angiogenesis. Cell Death Dis 4:e808

Wilhelmus MMM, van Dam AM, Drukarch B (2008) Tissue transglutaminase: a novel pharmacological target in preventing toxic protein aggregation in neurodegenerative diseases. Eur J Pharmacol 585:464-472

Wityak J, Prime ME, Brookfield FA et al (2012) SAR development of lysine-based irreversible inhibitors of transglutaminase 2 for Huntington's disease. ACS Med Chem Lett 3:1024-1028

Wodtke R, Steinbach J, Pietzsch J et al (2013) Festphasensynthese von selektiv mono-fluorbenzoylierten Polyaminen zur in-vivoAdressierung von Transglutaminasen und Polyamin-Transportern. NuklearMedizine 51:A71

Zedira GmbH, Buechold C, Gerlach U, Hils M et al (2014) Pyridinone derivatives as tissue transglutaminase inhibitors. WO2014012858 (A1)

Zemskov EA, Janiak A, Hang J et al (2006) The role of tissue transglutaminase in cell-matrix interactions. Front Biosci 11:1057-1076 